\title{
Elektronenmikroskopische Untersuchungen an Anaitides mucosa (Annelida, Polychaeta). Cuticula und Cilien, Schleimzellen und Schleimextrusion
}

\author{
K. Hausmann \\ Lehrstuhl für Zellenlehre der Universität Heidelberg; Im Neuenheimer Feld 230, \\ D-6900 Heidelberg, Bundesrepublik Deutschland
}

\begin{abstract}
Electron microscopical studies on Anaitides mucosa (Annelida, Polychaeta). Cuticle and cilia, mucous cells and mucus extrusion. Two components, a basal cuticle and an epicuticle, make up the cuticle of $A$. mucosa. The basal cuticle consists of collagen fibrils, which are arranged in about 20 layers. The orientation of the fibrils changes rectangularly from one layer to the next. Fine filaments interweave the basal cuticle. The epicuticle, which is covered by a layer of electron dense material, is composed of irregularly arranged thin filaments. Branched microvilli of the epidermal cells penetrate the cuticle. Bacteria are found in the basal cuticle. Dorsally each segment has a band of densely packed smooth cilia. Laterally and partly ventrally aggregates of cilia are observed. These cilia exhibit apically artificial swellings. At least six different mucous cells are observed in the epidermis, morphologically distinguishable by the structure of the secretion products. Mucus is secreted via exocytosis through cuticular pores. During this process the mucus might expand. The secreted mucus consists of filamentous subunits.
\end{abstract}

\section{EINLEITUNG}

Anaitides mucosa ist ein zu den Phyllodociden gehörender Polychaet, der beispielsweise in den Wattgebieten der deutschen Nordseeküste in relativ hoher Populationsdichte auftreten kann (Dörjes, 1970; Linke, 1939). Vom ökologischen Standpunkt her gesehen spielt $A$. mucosa sicher eine wesentliche Rolle, wenn man die Watt-Makrofauna als Nahrungspotential für Brut- und Gastvögel auffaßt (Farke \& Hausmann, 1971).

Die Morphologie, insbesondere die Ultrastruktur dieses Wurmes ist bislang noch nicht im Detail bearbeitet worden. Die vorliegende Untersuchung beschäftigt sich daher im ersten Teil mit der Organisation der Cuticula sowie der Struktur epidermaler Cilienbänder und -aggregate von A. mucosa. Der zweite Teil der Arbeit hat die Morphologie der Schleimzellen sowie die Art der Schleimextrusion zum Inhalt.

Schleimextrusion ist eine geläufige Erscheinung bei Polychaeten. Der Schleimausscheidung werden unterschiedliche Funktionen zugeschrieben (vgl. Friedrich, 1964; Richards, 1978). So steht dieser Vorgang im Zusammenhang mit dem Bau oder der Verfestigung von Wohnröhren. Schleimabsonderung an den Tentakeln bestimmter sessiler Polychaeten dient dem Nahrungserwerb. Weiterhin kennt man eine plötzlich 
erfolgende, massive Schleimausscheidung über den ganzen Körper. Diese Erscheinung wird als Schutzverhalten gegenüber Feinden angesehen. Insbesondere für die Phyllodociden ist dieses Verhalten charakteristisch.

Es existierten eine ganze Reihe von Arbeiten über die Schleimzellen verschiedener Annelidenspecies (vgl. Richards, 1978; Storch \& Welsch, 1972). Bislang haben die Phyllodociden allerdings noch keine entsprechende Beachtung gefunden.

\section{MATERIAL UND METHODEN}

Anaitides mucosa wurde im Norderneyer Watt gesammelt. Da A. mucosa unter Normalbedingungen auf sehr geringe Reize hin eine dicke Schleimhülle ausscheidet, die für die Untersuchung sehr hinderlich ist, wurden die Tiere, bevor sie in einem eisgekühlten Glutaraldehyd-Osmium-Gemisch für 1 Stunde fixiert wurden (Franke et al., 1969), mehrere Stunden bei ca. $4{ }^{\circ} \mathrm{C}$ im Kühlschrank aufbewahrt. Die Entwässerung der fixierten Objekte erfolgte in einer Alkoholreihe steigender Konzentration.

Für die Rasterelektronenmikroskopie wurden die Tiere danach in Freon 12/13 überführt, in einer Critical-Point-Apparatur getrocknet und in einer Sputter-Anlage mit Gold beschichtet (weitere Details vgl. Barthlott \& Ehler, 1977). Zur Untersuchung stand ein Cambridge-Rasterelektronenmikroskop Stereoscan 600 zur Verfügung.

Für die Transmissionselektronenmikroskopie wurden die unmittelbar zu Beginn der Fixierung in 1-2 mm lange Stücke zerteilten Tiere in Epon 812 eingebettet und mit einem Reichert-Ultramikrotom geschnitten. Die Nachkontrastierung der Schnitte erfolgte mit Uranylacetat (Watson, 1958) und Bleicitrat (Reynolds, 1963). Die Präparate wurden in einem Philips-EM-400-Transmissionselektronenmikroskop untersucht.

\section{ERGEBNISSE}

\section{Allgemeine Morphologie}

Anaitides mucosa wird zwischen 10 und $15 \mathrm{~cm}$ lang und weist einige hundert gleichgestaltete Segmente auf. Ausnahmen bilden das Pronotum sowie das Pygidium (Abb. 1a). Der Kopf besitzt einen ausstülpbaren Rüssel, 4 Paar Antennen und 4 Paar Tentakelcirren. Das Pygidium ist mit zwei Analcirren versehen. Die Dorsalcirren der Parapodien sind in für Phyllodociden charakteristischer Weise paddelartig vergrößert (Abb. 1b), wohingegen die Ventralcirren deutlich kleiner sind (Abb. 1c). Pro Parapodium findet sich ein Borstenbüschel (Abb. 1b, c).

A. mucosa ist, wie die meisten Phyllodociden, lebhaft gefärbt. Die Färbung ist in einem regelmäßigen Muster angelegt, das sich in jedem Segment wiederholt (Abb. 1a). Rücken- und Bauchseite zeigen unterschiedliche Farbmuster.

\section{Cuticula}

Die Cuticula von Anaitides mucosa zeigt den für Anneliden typischen Aufbau. Das beherrschende Element ist ein mehrere Schichten starkes Fasergitter ( = basale Cuticula) aus parallel zur Körperoberfläche und im Wechsel der Schichten jeweils senkrecht zueinander verlaufenden Kollagenfibrillen (Abb. 2a, b und Abb. 3a). Die Fibrillen 

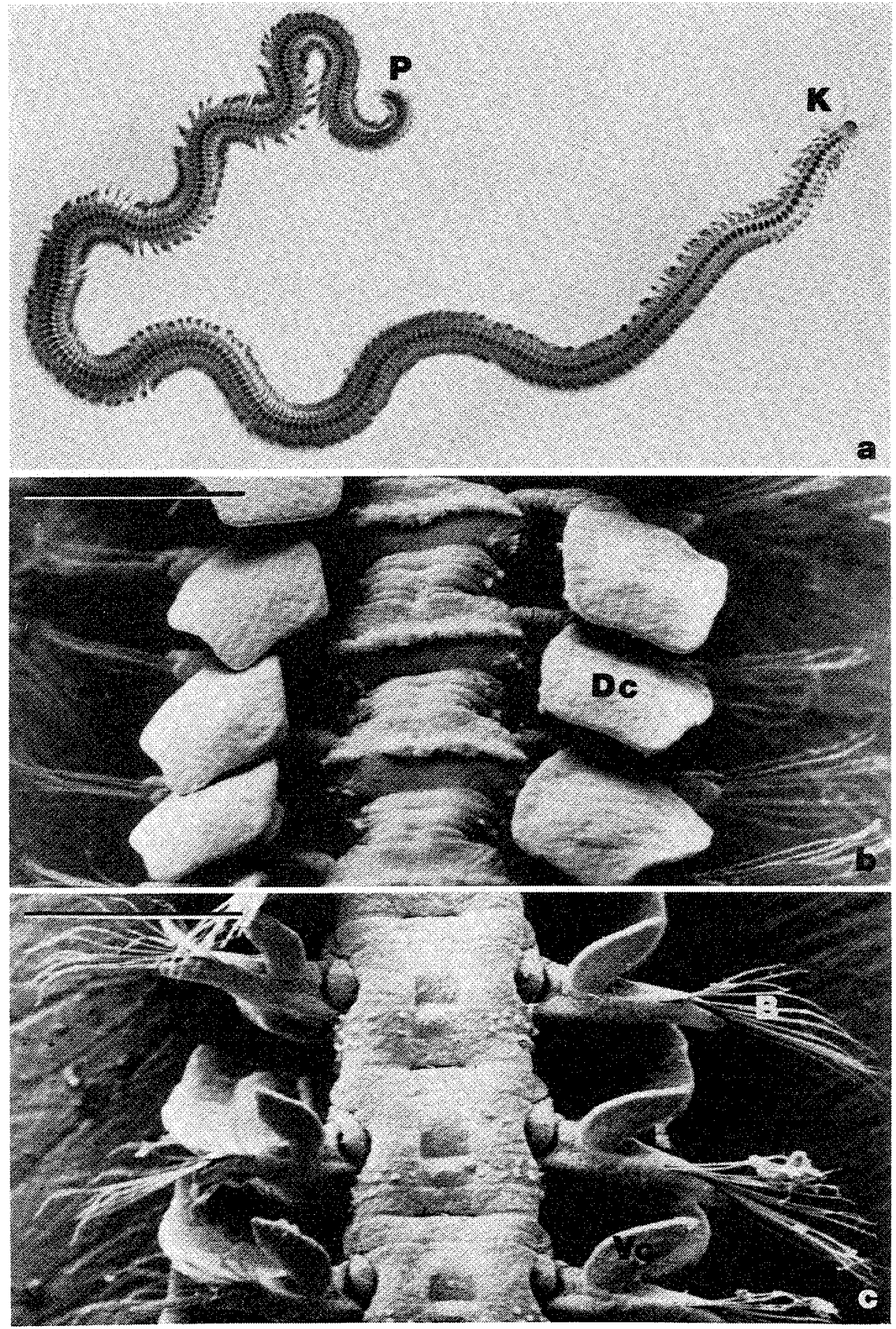

Abb. 1. Anaitides mucosa. (a) Lebendaufnahme; (b) und (c) rasterelektronenmikroskopisch (REM). (a) Habitus. K - Kopf; P - Pygidium. (b) Dorsalseite. Dc - Dorsalcirrus. (c) Ventralseite. B - Borsten; Vc-Ventracirrus. Der Maßstrich in (b) und (c) gibt $1 \mathrm{~mm}$ an. Vergr.: (a) ca. $2 x_{i}$ (b) und (c) $30 \times$ 

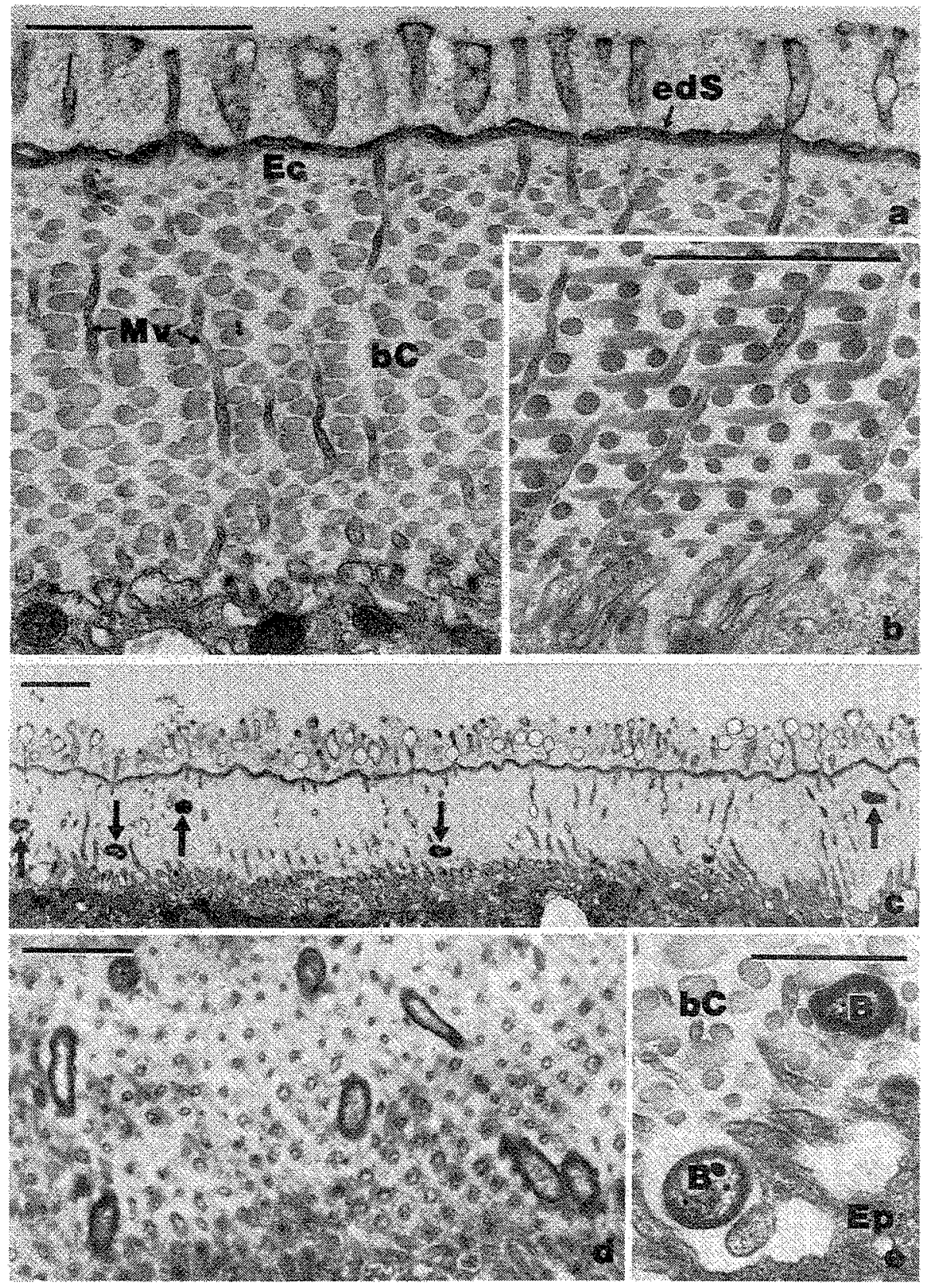

Abb. 2. Cuticula. Transmissionselektronenmikroskopisch (TEM). (a) und (b) Querschnitt durch die Cuticula. Zwei Lagen von Kollagenfibrillen verlaufen senkrecht zueinander (vgl. Abb. 3 a). (c-e) Bakterien (B) in der Cuticula (IC], Pfeile), bC - basale Cuticula; Ec - Epicuticula; edS - elektronendichte Schicht, Ep - Epidermis; Mv - Mikrovili. Der Maßstrich in (a-d) bedeutet $1 \mu \mathrm{m}$, in (e) $0,5 \mu \mathrm{m}$. Vergr: (a) $30000 \times_{i}$ (b) $32000 \times_{i}$ (c) $9000 \times_{i}$ (d) $15000 \times_{i}$ (e) $40000 \times$ 


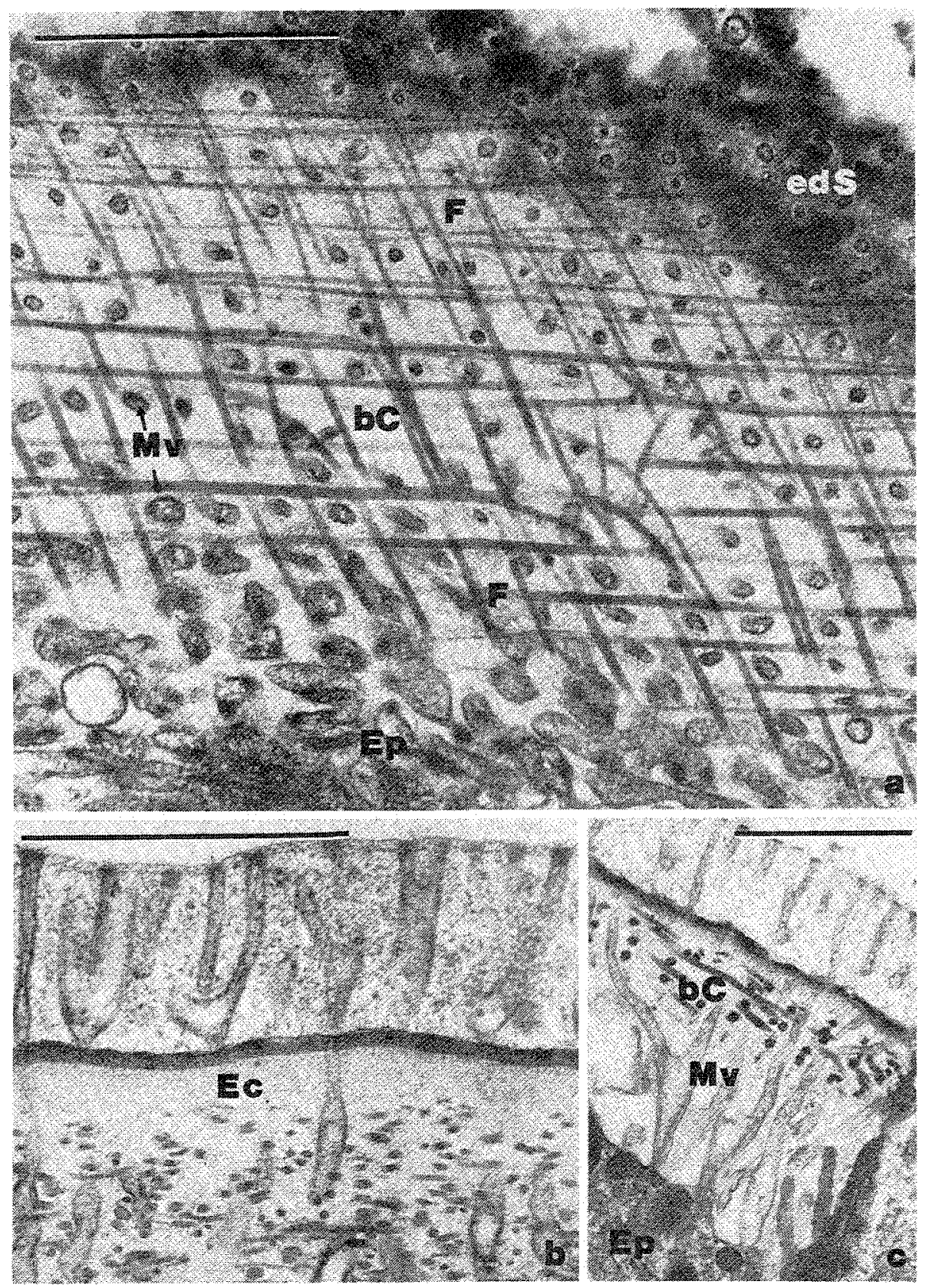

Abb. 3. Cuticula (TEM). (a) Schrägschnitt durch die Cuticula. Zwischen den Kollagenfibrillen finden sich zahlreiche Filamente (F). bC - basale Cuticula; edS - elektronendichte Schicht; EpEpidermis; Mv - Mikrovilli. (b) und (c) Mikrovilli (Mv) der Epidermiszellen (Ep) können oberhalb der Epicuticula (Ec) und in der basalen Cuticula (bC) verzweigt sein. Die Maßstriche geben $1 \mathrm{um}$ an. Vergr.: (a) $40000 \times_{i}$ (b) $23000 \times_{i}$ (c) $43000 \times$ 

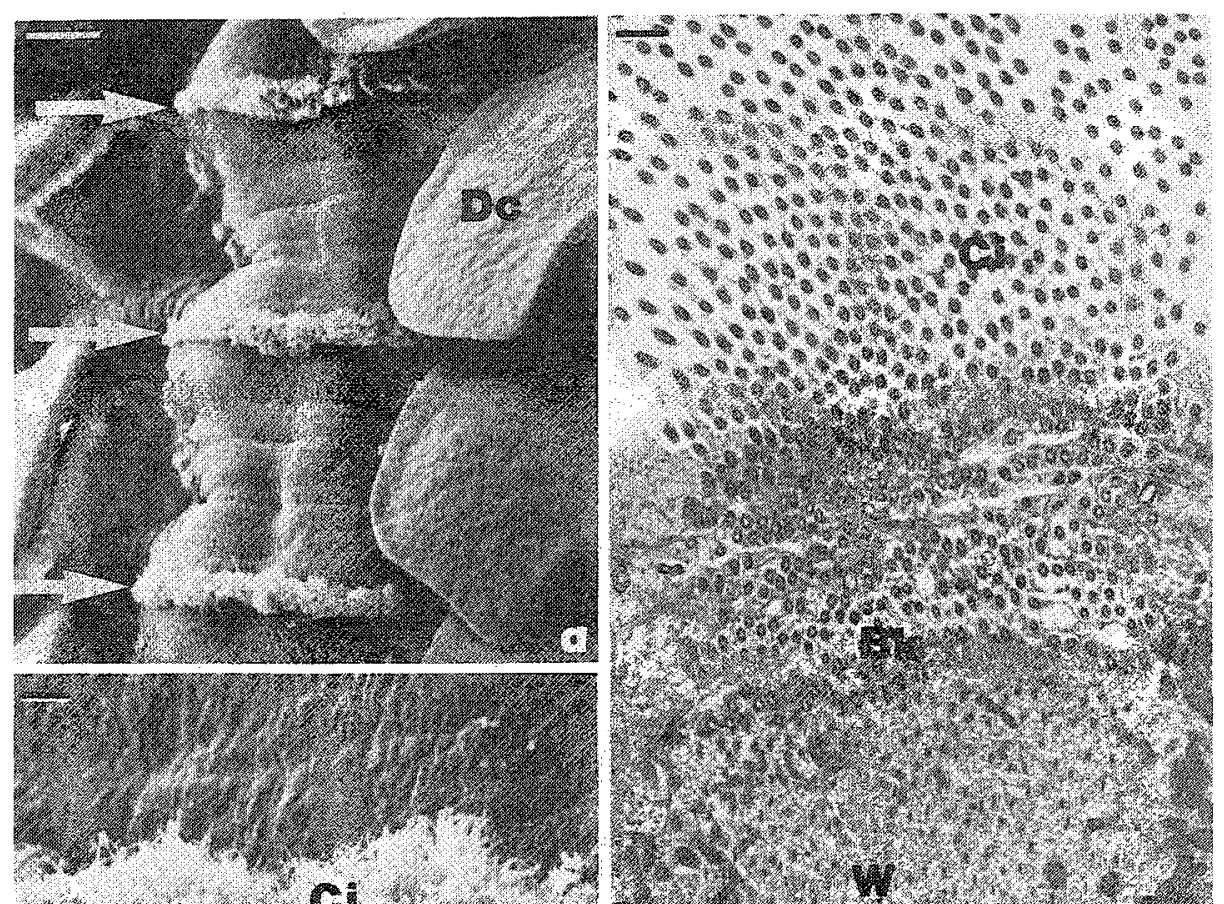

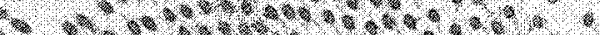

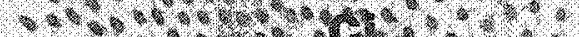

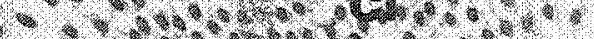

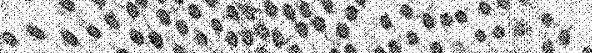

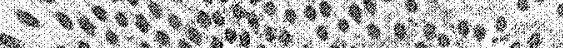

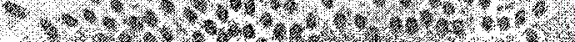
17.7.

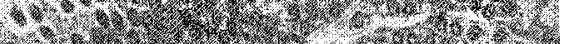

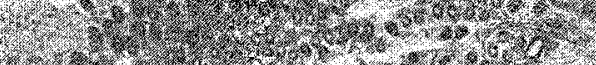
1. 3.

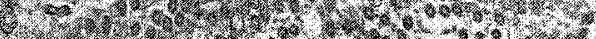
r. ,

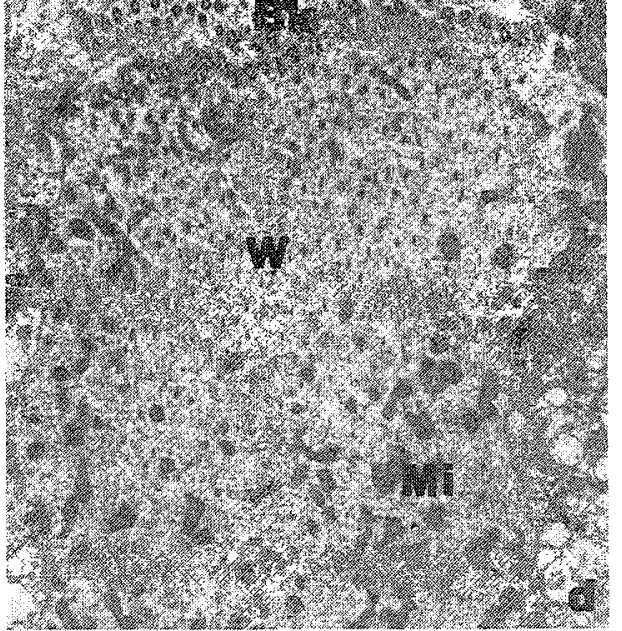
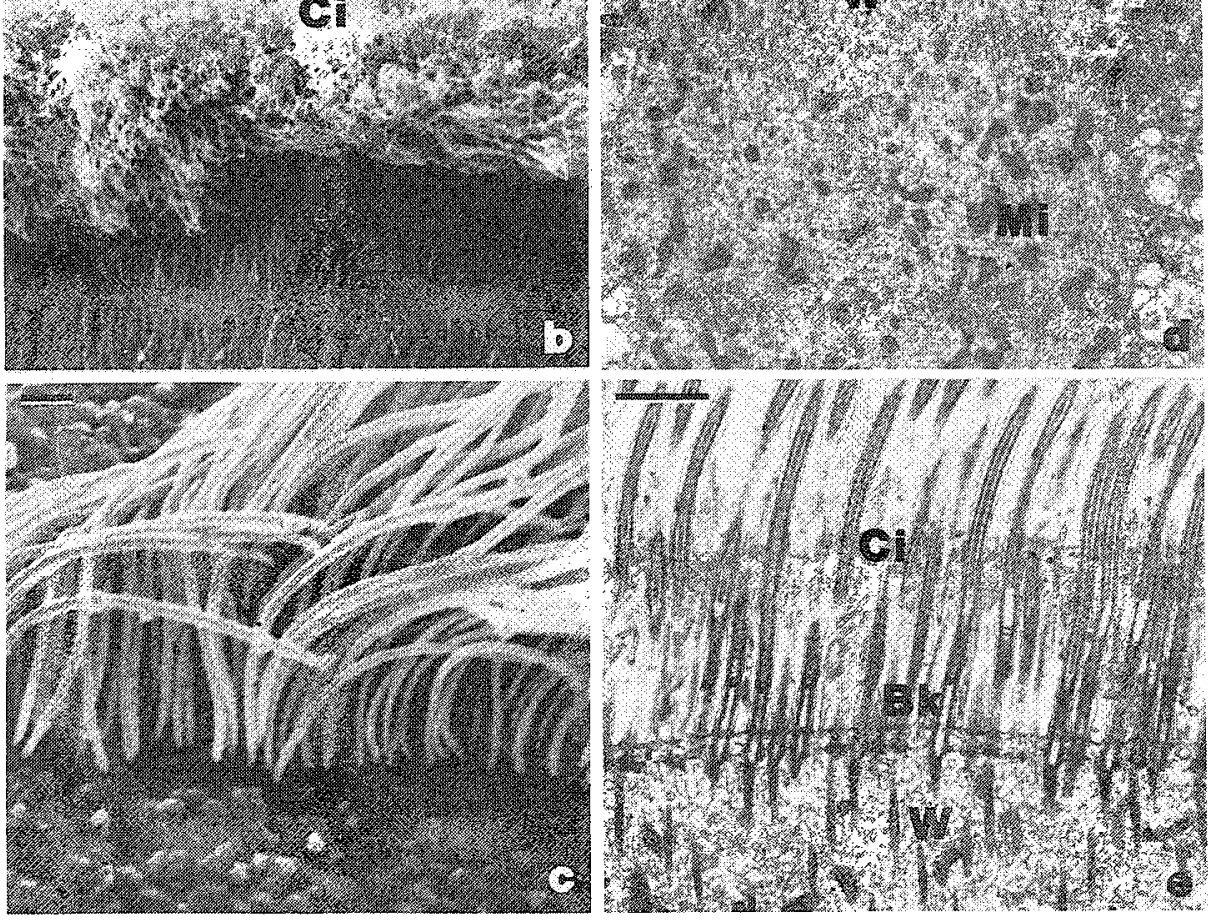

Abb. 4. Dorsales Wimpernband in REM- (a-c) und TEM-Aufnahmen (d) und (e). Jedes Segment besitzt auf Höhe der Parapodienansatzstelle ein Wimpernband ([a], Pfeile), das aus zahlreichen Cilien (Ci) besteht (b) und (c). Cilienschäfte (Ci), Basalkörper (Bk) und Wurzelstrukturen (W) im Schräg- (d) und Längsschnitt (e). Der Maßstrich in (a) bedeutet $100 \mu \mathrm{m}$, in (b) $10 \mu \mathrm{m}$, in (c-e) $1 \mu \mathrm{m}$. Vergr.: (a) $75 \times_{\text {; }}$ (b) $450 \times_{\text {; }}$ (c) $5000 \times_{i}$ (d) $5200 \times_{i}$ (e) $9400 \times$ 

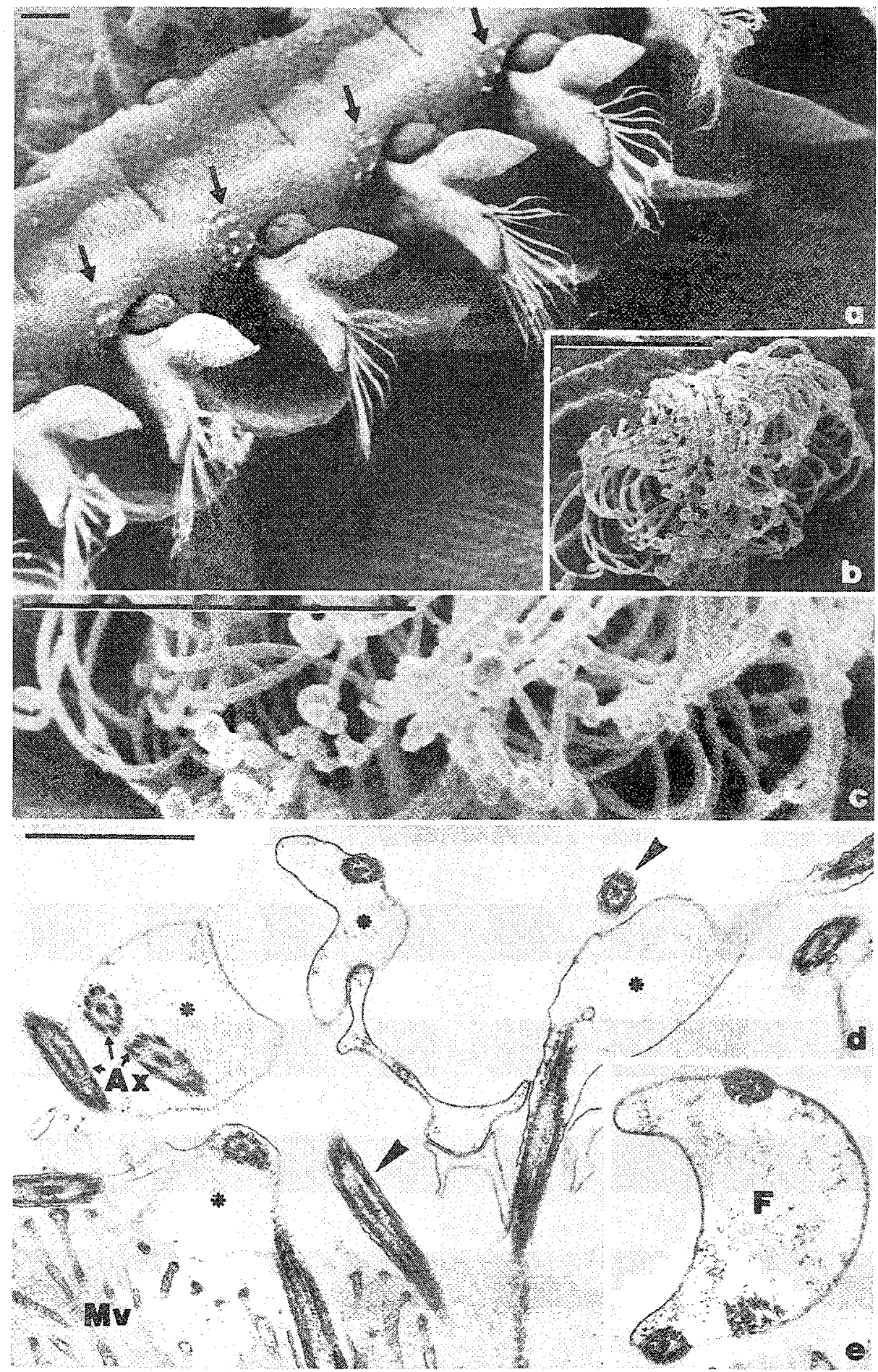

Abb. 5. Wimpernhügel im REM- (a-c) und TEM-Bild (d) und (e). (a) Wimpernhügel zwischen den Parapodien (Pfeile). (b) und (c) Wimpernspitzen mit Auftreibungen. (d) und (e) Die Cilienschäfte sind aufgebläht ([d], 化) und mit fädigem Material gefüllt ([c], F). Das Axonem (Ax) ist bis zu dreimal in einem Cilienquerschnitt getroffen. Die Pfeilköpfe in (d) weisen auf gewohnte Cilienquer- und -längsschnitte. Mv-Mikrovilli. Die Maßstriche in (a-c) bedeuten $100 \mu \mathrm{m}$, in (d) $1 \mu \mathrm{m}$.

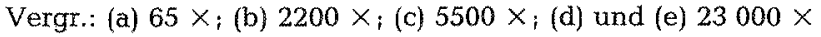


wechseln, wie Tangentialschnitte zeigen (Abb. 3a), bisweilen die Richtung. Durchzogen wird das ganze Gitter von feinsten, regellos angeordneten Filamenten (Abb. 3a). Die im Querschnitt runden und kompakten Kollagenfibrillen zeigen auch im Längsschnitt eine homogene Feinstruktur. Nach außen hin wird die basale Cuticula durch die Epicuticula, welche durch einen feinfaserigen bis homogenen Strukturaspekt gekennzeichnet ist, abgeschlossen (Abb. 2a und 3b). Der Epicuticula ist ein sehr kontrastreiches, bisweilen lamellenartig geschichtetes Material aufgelagert (Abb. 2a und Abb. 3b).

Von den Epidermiszellen ausgehend ziehen zahlreiche, mit mäßig dichtem Plasma gefüllte Mikrovilli durch das regelmäßige Fibrillengitter der basalen Cuticula und durchstoßen die der Epicuticula aufgelagerte kontrastreiche Schicht. Oberhalb dieser Schicht sind die Mikrovilli in einer dickeren Lage aus grobfädigem bis granulärem Material eingebettet (Abb. 2a und Abb. 3b, c). Nicht selten lassen sich bei den in diesem Bereich durchweg dilatierten Mikrovilli Verzweigungen feststellen (Abb. 3b). Mikrovilliverzweigungen in der basalen Cuticula sind erheblich seltener anzutreffen (Abb. 3c). Der Mikrovillusapex ist stets durch eine besonders opake Zone gekennzeichnet (Abb. 2a und Abb. 3b).

Häufig finden sich in der basalen Cuticula zwischen den Kollagenfibrillen nahe der Oberfläche wie auch dicht an der Epidermis längliche Bakterien (Abb. 2c, d, e). Es wurden speziell in der der Epicuticula aufgelagerten elektronendichten Schicht keine auffälligen Löcher entdeckt, die Hinweise auf den Eindringungsort der Bakterien hätten geben können. Es wurden auch keine Anzeichen einer Zerstörung der Cuticula oder der Epidermiszellen um die Bakterien herum festgestellt.

\section{Cilien}

Jedes Segment besitzt auf der Dorsalseite ein Wimpernband, das an den Körperflanken endet (Abb. 1b und Abb. 4). Bisweilen sind die Bänder - möglicherweise infolge von Verletzungen - regellos unterbrochen. Die einzelnen Cilien zeigen im rasterelektronenmikroskopischen Bild bis auf einige anhaftende Schmutzpartikel in der Regel eine bis zur Spitze hin glatte Oberfläche (Abb. 4c).

In Flachschnitten durch die Region der Wimpernbänder (Abb. 4d) zeichnen sich die Zellen, aus denen die Cilien entspringen, durch ein im Vergleich mit den benachbarten Epidermiszellen relativ homogenes Grundplasma aus, in dem zum einen die typischerweise quergestreiften Wurzelstrukturen der Cilien und zum anderen eine Vielzahl von Mitochondrien als dominierende Zellorganellen zu finden sind. Die Basalkörper der Cilien reichen deutlich über das sonstige Zellniveau hinaus (Abb. 4e).

Die für die anderen Körperbereiche belegte Cuticulastruktur ist im Bereich der Wimpernbänder aufgehoben. Es finden sich keine Kollagenfibrillen und Mikrovilli. Statt dessen ist ein mehr oder weniger fädiges bis amorphes Material vorhanden, das eine ungefähr genauso weite Ausdehnung hat wie die normale Cuticula (Abb. 4e). Die Cilienaxoneme zeigen bis in die Cilienspitze hinein den gewohnten Strukturaspekt.

Anders ist die Situation bei den hauptsächlich lateral zwischen den Parapodien und - weniger dicht - auch auf der Ventralseite angeordneten Wimpernhügeln (Abb, 5a). Die einzelnen Cilien dieser 100-150 $\mu \mathrm{m}$ großen Aggregate zeichnen sich im rasterelektronenmikroskopischen Bild stets dadurch aus, daß ihre Spitzen blasig aufgetrieben sind (Abb. 5b, c). Dünnschnitte durch entsprechende Cilienabschnitte geben eine Innen- 
struktur wieder, die vom gewohnten Bild erheblich abweicht (Abb. 5d, e): Nicht nur, daß in Querschnitten das Axonem bis zu dreimal getroffen sein kann, sondern auch die Axonemstruktur selbst erscheint häufig sehr mangelhaft erhalten. Darüber hinaus ist der ungewöhnlich große Cilieninnenraum bis auf ein lockeres Netzwerk aus feinen Fäden optisch leer.

\section{Schleimzellen}

Die Schleimzellen von $A$. mucosa zeigen, wie aus einem Übersichtsbild hervorgeht (Abb. 6), sehr verschiedenartige Feinstrukturen. Verglichen mit den aus der Literatur her bekannten Schleimzellen (vgl. Richards, 1978; Storch \& Welsch, 1972), gibt es mindestens sechs morphologisch unterscheidbare Schleimzelltypen (Abb. 7, 8,9), die in zwei Größenklassen eingeteilt werden können: Die länglichen Schleimzellen gehen deutlich über das epidermale Gewebe hinaus ins Innere des Tieres hinein (Abb. 7), während die rundlich-ovalen Zellen eine ähnliche Ausdehnung wie die Epidermiszellen haben (Abb. 8).

Es gibt sehr lange und schmale Schleimzellen, deren Inhalt grobfädig erscheint (Abb. 7a). Ein zweiter Typ zeigt einen feinfädigen Strukturaspekt. Der gesamte Inhalt ist in - meist nicht scharf gegeneinander abgegrenzte - Untereinheiten gegliedert (Abb. 7b). Möglicherweise handelt es sich bei diesen Zellen um unreife Stadien des ersten Typs. Der dritte Zelltyp schließlich ist mit Schleimpaketen angefüllt, die je nach Schnittrichtung rund oder weitausgezogen, länglich-oval erscheinen. Der Schleim ist teils feinfädig, teils grobretikulär. Das Übersichtsbild (Abb.6) läßt vermuten, daß die grobretikulären Strukturen den reifen Zustand der entsprechenden Schleimzellen widerspiegeln.

Es finden sich häufig Schleimzellen, die ausschließlich mit deutlich gegeneinander abgegrenzten Paketen aus feinfilamentösem Material angefüllt sind (Abb. 6). Von der Größe her gesehen liegt dieser Zelltyp zwischen den sehr großen und den kleinen Schleimzellen. Das gleiche gilt für einen Zelltyp, der mit länglich-ovalen, sehr osmiophilen Granula angefüllt ist (Abb. 6 und 9).

Die Schleimzellen mit der Größe der Epidermiszellen besitzen distinkt geformte Sekretprodukte. Am auffälligsten sind die Zellen, die mit sehr kontrastreichen, mehr oder weniger regelmäßig schwammartig durchbrochenen Granula angefüllt sind (Abb. 8a). Die Peripherie der Granula ist aufgelockert (aufgebläht?).

Ein weiterer Zelltyp erinnert an den soeben beschriebenen insofern, als auch hier Granula mit mehr oder minder gleichförmigen Strukturen vorliegen (Abb. 8b). Jedoch beruht das Muster auf Verdichtungen eines ansonsten filamentösen Materials. Die einzelnen Sekretgranula können unterschiedlich kontrastreich sein.

Andere Strukturverhältnisse liegen bei den Zellen vor, die peripher mit Mikrotubuli ausgekleidet sind (Abb. 8c). Hier finden sich kleine Sekretvesikel bzw. -zisternen, die deutlich von einer Membran umgeben und mit elektronendichtem, amorphem Material gefüllt sind.

\section{Schleimextrusion}

Die Extrusion der Schleimzellen erfolgt über einen Porus in der Cuticula (Abb. 9). Ein Charakteristikum des Schleimzellenapex ist es, daß mehr oder weniger deutlich 


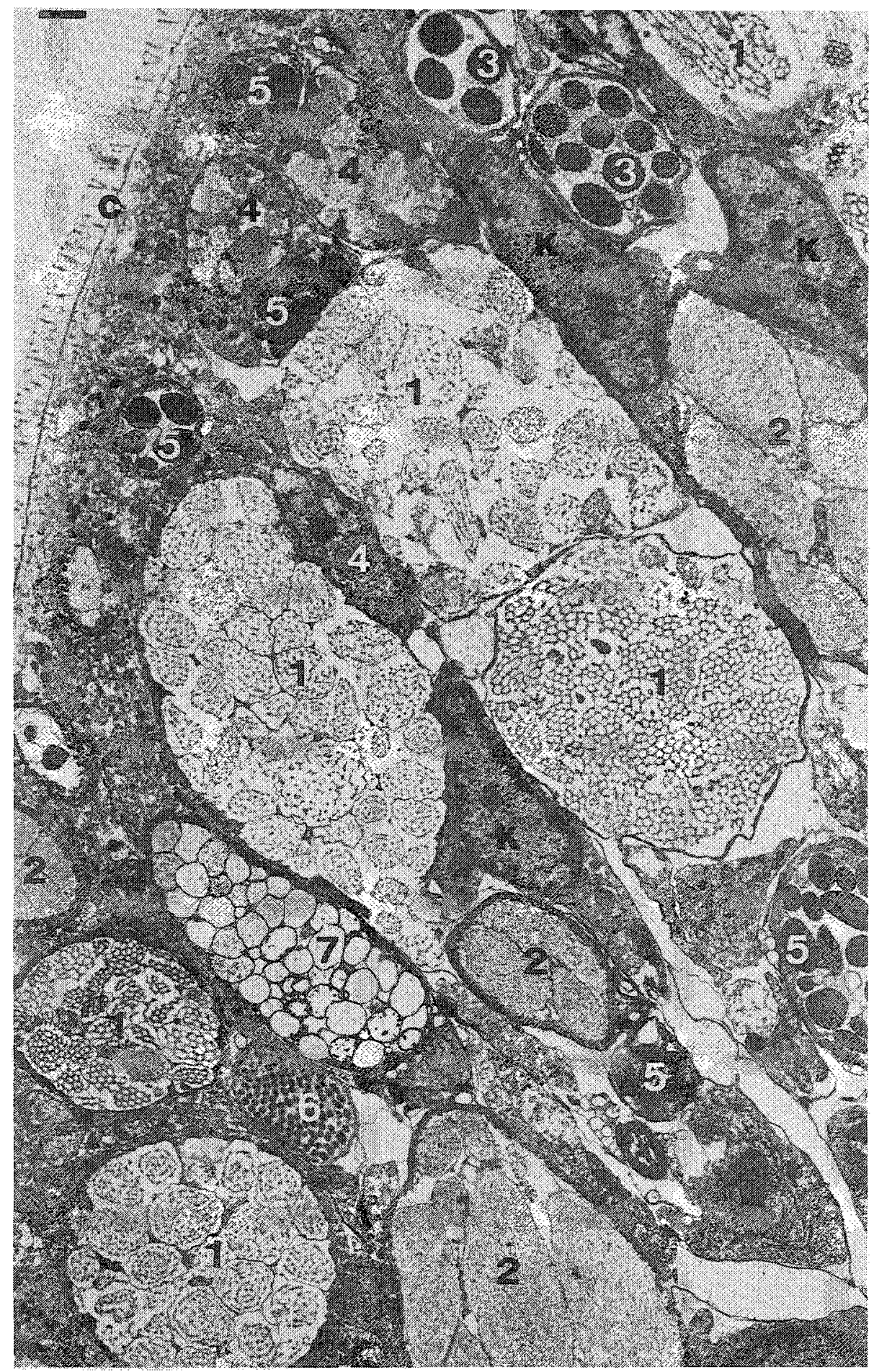

Abb. 6. Ubersicht mit verschiedenen Schleimzelltypen (1-7). C-Cuticula; K-Kern. Der Maßstrich bedeutet $1 \mathrm{am}$. Vergr $6600 \times$ 


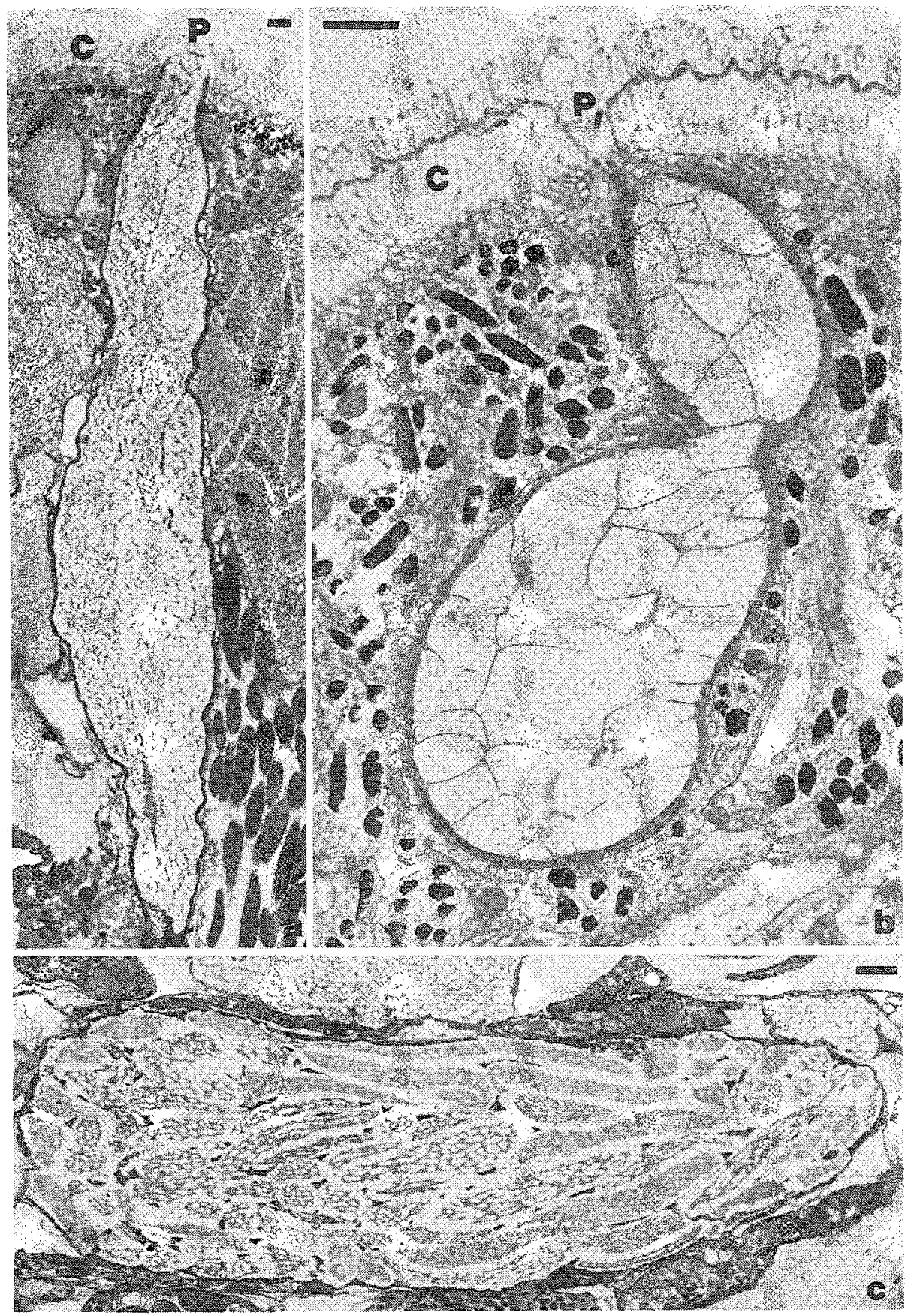

Abb. 7. Lange Schleimzellen. Möglicherweise stellen die hier abgebildeten Zellen verschiedene Entwicklungsstadien eines Typs dar (vgl. 1 in Abb. 6). C - Cuticula; P - Porus. Die Maßstriche bedeuten $1 \mu \mathrm{m}$. Vergr.: (a) $3400 \times_{i}$ (b) $10000 \times_{i}$ (c) $5300 \times$ 


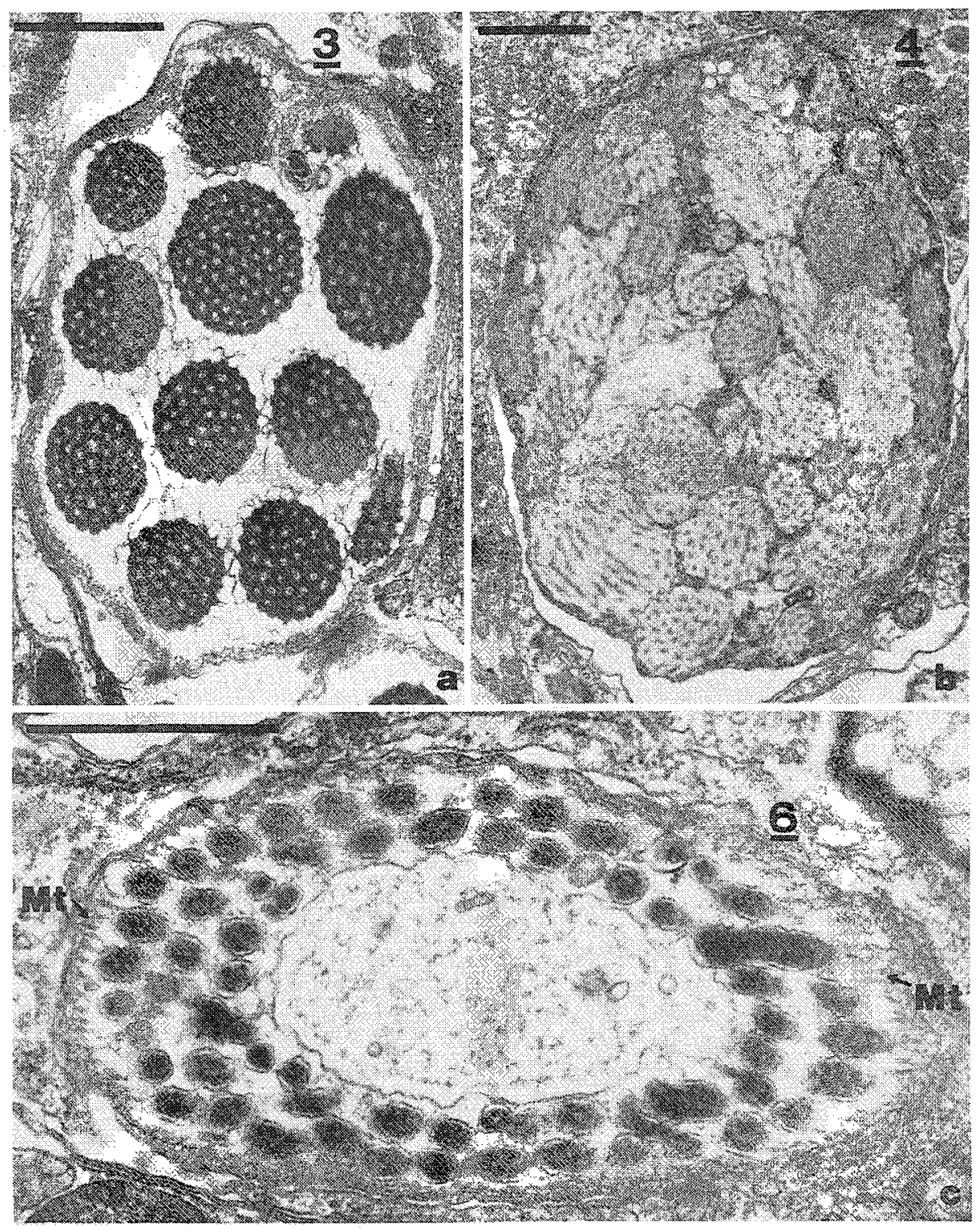

Abb. 8. Kleine Schleimzellen mit verschieden strukturiertem Inhalt. 3,4 und 6 verweisen auf die Numerierung in Abb. 6. Mt-Mikrotubuli. Die Maßstriche bedeuten $1 \mu \mathrm{m}$. Vergr.: (a) $19000 \times_{i}$ (b) $14000 \times$ : (c) $32000 \times$

Mikrovilli ausgebildet sind. Der Schleim wird teils in Form von kormpakten Paketen, wie er in der Zelle vorgelegen hat; teils unter Auflockerung als fädiges Material nach außen abgegeben (Abb, 9).

Der ausgeschiedene Schleim läßt im Rasterelektronenmikroskop noch deutlich strangförmige, miteinander verklebte Untereinheiten erkennen (Abb. 10a). Schnittbil- 


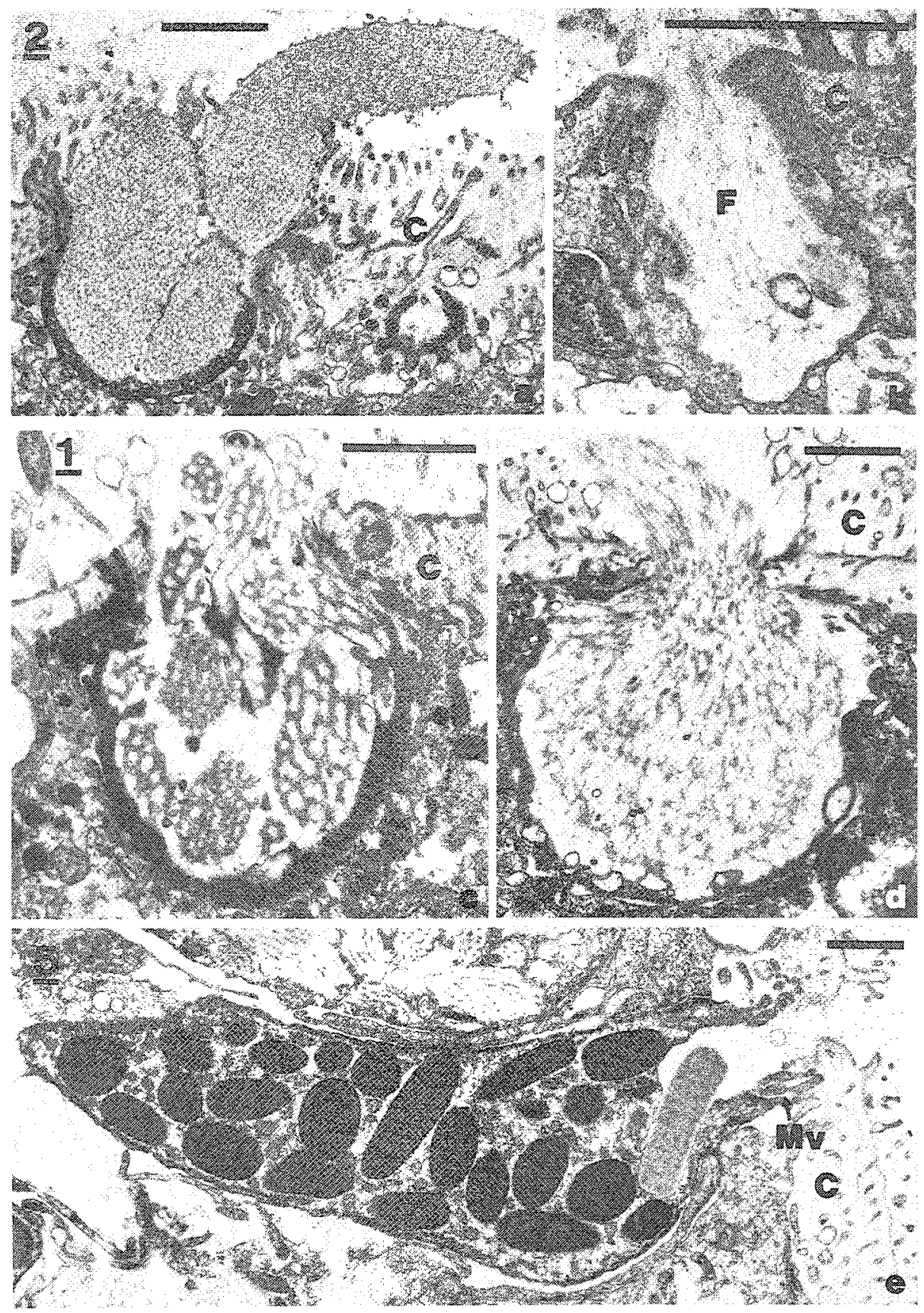

Abb. 9. Schleimzellen während der Extrusion. Es werden sowohl kompakte Schleimpakete ([a], [c], [e]) als auch aufgelockerte Schleimfilamente (F) ausgeschieden ([b], und [d]). 1,2 und 5 verweisen auf die Numerierung in Abb.6. C - Cuticula; Mv - Mikrovilli. Die Maßstriche bedeuten $1 \mu \mathrm{m}$. Vergr.: (a) $14000 \times$; (b) $32000 \times$; (c) $18000 \times$; (d) $13000 \times$; (e) $10000 \times$ 


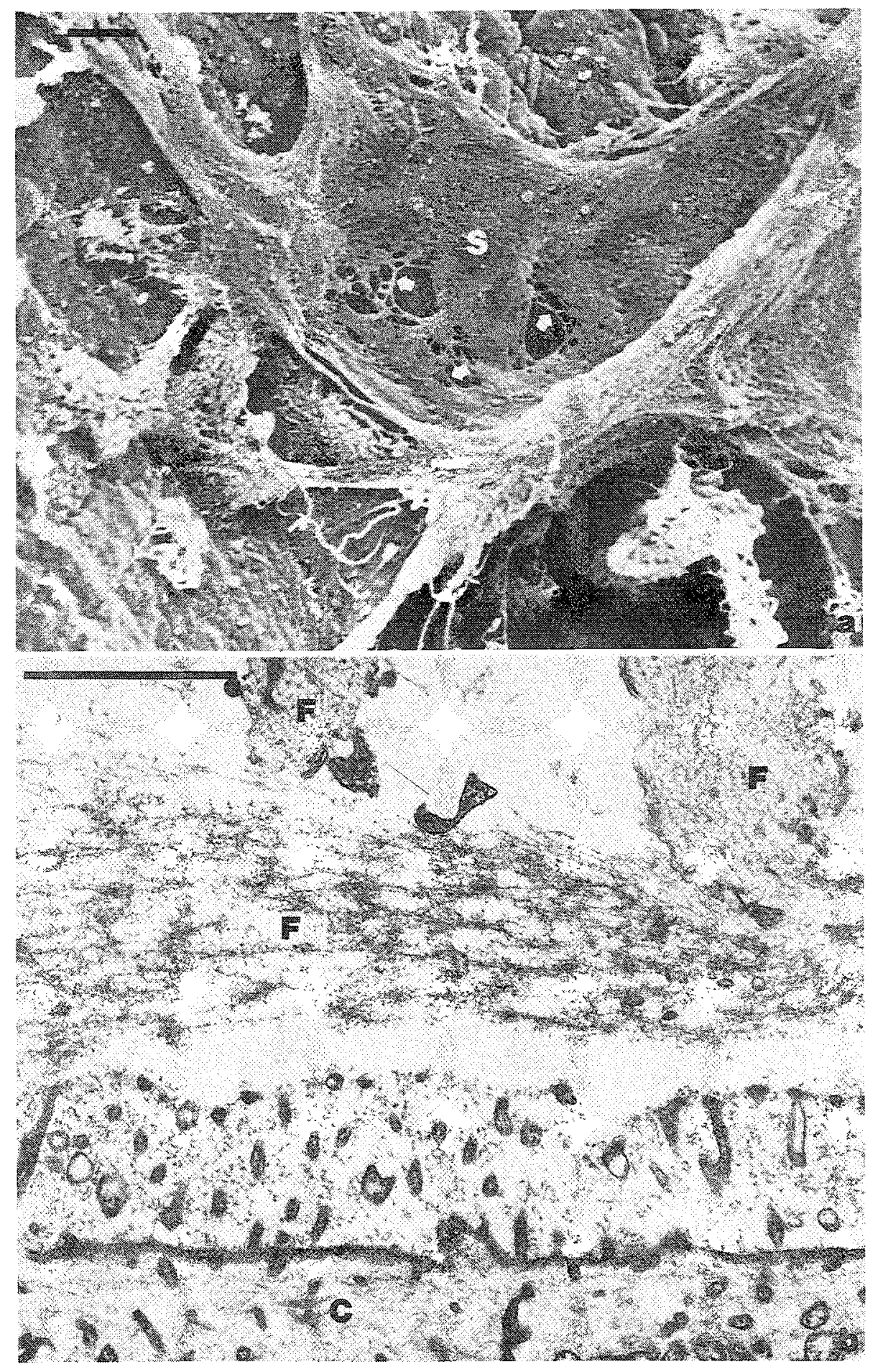

Abb. 10. Ausgeschiedener Schleim (S). Im REM-Bild erkennt man strangförmige Untereinheiten des Schleimes ([a], Pfeile). TEM-Bilder belegen die filamentöse Natur dieser Stränge ([b], F). Der Maßstrich in (a) gibt $10 \mu \mathrm{m}$, in (b) $1 \mu \mathrm{m}$ an. Vergr.: (a) $1000 x_{\text {; }}$ (b) $30000 \times$ 
der belegen, daß außerhalb des Tieres relativ dichter Schleim aus sehr feinen Filamenten mit grobfädigem, aufgelockertem Schleimmaterial verbunden sein kann, in dem noch andeutungsweise eine Regelmäßigkeit vorliegt (Abb. 10b).

\section{DISKUSSION}

Die Polychaetenepidermis und speziell der Cuticulakomplex werden seit Jahrzehnten eingehend untersucht. Neben generellen Strukturbeschreibungen und der biochemischen Untersuchung der Cuticulabestandteile (zusammenfassende Darstellung bis 1961: Friedrich, 1964; neuere Literatur: Richards, 1978) sind sowohl vergleichendmorphologische Zusammenstellungen des Epidermis- und Cuticulaaufbaus (Storch \& Welsch, 1970) als auch Untersuchungen zur Morphogenese (Eckelbarger \& Chia, 1978; Holborow, 1971; Holborow et al., 1969) sowie zur Regeneration der Polychaetencuticula (Humphreys \& Porter, 1976) publiziert worden. Die vorliegende Arbeit beschreibt einige Strukturbesonderheiten des Cuticulakomplexes von $A$. mucosa, die bislang noch nicht im Detail dargelegt worden sind.

Das Rasterelektronenmikroskop vermittelt einen sehr plastischen Eindruck vom generellen Bau des Wurmes. Derartige Bilder erleichtern die exakte Lokalisierung von Strukturen, wie in diesem Fall zum Beispiel die der Wimpernhügel, außerordentlich. Darüber hinaus können die Befunde solcher Untersuchungen auch für systematische Fragestellungen verwandt werden. Und so sind bereits Ergebnisse von rasterelektronenmikroskopischen Studien zur Struktur der Elytrenoberflächen einiger Polychaeten veröffentlicht worden, die insbesondere hinsichtlich der systematischen Einordnung der untersuchten Species von Relevanz sind (Anton-Erxleben, 1977).

Wie beschrieben, ist $A$. mucosa lebhaft gefärbt. Ein Grund für diese Färbung soll darin liegen, daß es bei seitlich eintreffendem Licht infolge der Strukturbesonderheiten der Cuticula zu Interferenzfarben kommt (Friedrich, 1964; Richards, 1978). Die Cuticula von $A$. mucosa ist in der Tat so regelmäßig aufgebaut, daß eine derartige Interpretation zumindest einen Teil der Färbung erklärt. Es kommen aber sicher auch noch Pigmenteinlagerungen in der Epidermis mit hinzu.

Beim Aufbau der basalen Cuticula ist zweierlei bemerkenswert: (1) Es finden sich zwischen den Kollagenfibrillen recht beträchtliche Mengen feinfilamentöser Strukturen, die ohne erkennbare Ordnung das Gitterwerk durchziehen. Vergleichbares Material findet sich beispielsweise in der fibrösen basalen Cuticula von einigen Vertretern der Familie Hesionidae (Westheide \& Rieger, 1978), bei denen jedoch das auffällige Gitterwerk aus Kollagenfasern fehlt. Möglicherweise handelt es sich im vorliegenden Fall um Kollagenfasern, die (noch) nicht zu dickeren Fibrillen vereinigt sind. (2) Die einzelnen Kollagenfibrillen, die im idealen Cuticulaquerschnitt äußerst regelmäßig Schicht um Schicht um $90^{\circ}$ gedreht - angeordnet sind, können, wie es bisweilen beobachtet wurde, ihren Verlauf ändern und um $90^{\circ}$ gebogen in die darüber- bzw. darunterliegende Faserschicht einschwenken. Unter Umständen wird durch diese Anordnung ein höherer Festigkeitsgrad in der basalen Cuticula erzielt.

Die in der basalen Cuticula nachgewiesenen Bakterien verursachen keinen erkennbaren Schaden am Tier. Demnach handelt es sich wohl bei den Bakterien um Kommensalen. Ähnliche Verhältnisse, das heißt, Kommensalismus, liegen auch bei den ebenfalls 
auf $A$. mucosa lebenden sessilen Ciliaten der Familien Epistylidae und Scyphiidae vor (Hausmann, 1980).

Die von der Epidermis durch den Cuticulakomplex bis zur Körperoberfläche dringenden Mikrovilli dienen dem Stoffaustausch zwischen umgebendem Medium und Epidermis (Storch, 1971). Es ist sehr wahrscheinlich, daß, wie durch die Verzweigung und somit beträchtliche Oberflächenvergrößerung der äußeren Mikrovillibereiche suggeriert wird, ein Stofftransport hauptsächlich von außen (umgebendes Medium) nach innen (Epidermis) erfolgt. Dafür sprechen auch die auffälligen (artifiziellen?) Aufblähungen der Mikrovilli in den elektronenmikroskopischen Bildern. Die elektronendichten Bereiche in den Mikrovilliapices können in diesem Zusammenhang als Hinweise für spezielle Anreicherungs- und Aufnahmevorrichtungen in der Membran dieser Zellausläufer gewertet werden.

Diese Interpretation schließt jedoch nicht aus, daß auch, je nach Bedarf, der umgekehrte Weg (von innen nach außen) möglich ist. In der Tat ist eine solche Alternative im Zusammenhang mit der Abschnürung bestimmter Granula von Mikrovilli von Polychaetenoocyten belegt worden (Eckelbarger \& Chia, 1978). Die Autoren dieser Arbeit weisen darauf hin, daß vergleichbare Oberflächengranula - bislang unbekannter Herkunft und Funktion - in der Literatur für eine ganze Reihe von adulten Polychaeten und Oligochaeten beschrieben worden sind. Vielleicht sind solche Bereiche, in denen die Mikrovilli von A. mucosa zusätzlich noch in der basalen Cuticula verzweigt sind, in besonderer Weise für eine Stoffabgabe, die nicht unbedingt in Form von Vesikelextrusionen erfolgen muß, prädestiniert.

Cilienbesatz beobachtet man häufig auf der Körperoberfläche von Polychaeten. So sind Tentakelanhänge (Gardiner, 1978; Schulte \& Riehl, 1976) und Kiemen (Storch \& Alberti, 1978) vielfach mit Wimpern versehen. In diesen Fällen sind sie für Bewegungsvorgänge verantwortlich, das heißt, sie betreiben den Transport von Nahrungspartikeln bzw. sie bewirken einen Wasserstrom. Die Funktion der segmental angelegten Wimpernbänder, die beispielsweise bei Ophryotrocha als neotenes Merkmal gedeutet werden (Storch, 1971), ist für A. mucosa unklar. Wenn sie eine Rolle bei der Fortbewegung spielen, dann sicherlich eine untergeordnete, da sie, verglichen mit den mächtigen, in erster Linie die Lokomotion bewirkenden Dorsalcirren der Parapodien, sehr kleine Strukturen sind. Anders ist die Situation zum Beispiel bei den Archianneliden. Hier kann man auf Grund der ganzflächigen Bewimperung der Ventralseite diesen Bewegungsorganellen durchaus lokomotorische Funktion zuschreiben (Friedrich, 1964).

Weiterhin finden sich Cilien im Zusammenhang mit Sinnesorganen (vgl. Mill, 1978). Bei den Wimpernhügeln von $A$. mucosa handelt es sich möglicherweise auch um Sinnesorgane, die wegen ihrer Lokalisation zwischen den Parapodien bei der Koordinierung der Fortbewegung eine Rolle spielen könnten. Die Wimpern dieser Aggregate zeigen jeweils eine auffällige Aufblähung der Spitzenregion, wie sie bei den Cilien der Wimpernbänder nicht festgestellt werden konnten. Derartige Wimpern sind in der Literatur als neuer, spezialisierter Cilientyp beschrieben und mit den Termini „Paddelcilien”, „Discocilien" oder "Klumpfußcilien" belegt worden (Ehlers \& Ehlers, 1978). Ehlers \& Ehlers (1978) stellen in Frage, ob hier tatsächlich Vitalstrukturen vorliegen. Auf Grund einer ganzen Reihe von Experimenten kamen die Autoren zu dem Schluß, daß es sich bei den Aufblähungen der Cilienspitzen um Artefakte handele, die primär durch bestimmte Puffer und weitere Zusätze zu den Fixiermedien induziert werden. Sie 
stellten fest, daß dieser Effekt vornehmlich bei Cilien von Sinneszellen beobachtet wird. Wir stimmen der Ansicht zu, daß die Aufblähungen Artefakte darstellen, weil wir bei eigenen Untersuchungen an Flagellaten und Ciliaten häufig genug die Entstehung dieser Aufschwellungen direkt im Vitalpräparat beobachten konnten, wenn ungünstige Bedingungen, wie beispielsweise Sauerstoffmangel, eintraten.

Die in dieser Arbeit dargelegte ungewöhnliche Anhäufung von Schleimzellen erklärt, warum $A$. mucosa zu einer so rapiden und massiven Schleimausscheidung befähigt ist, die bereits bei geringer Reizung des Wurmes beobachtet werden kann. Die verschiedenen Schleimzellen, die vorgefunden wurden, sind in ihrer Struktur auch von anderen Anneliden her bekannt (Storch \& Welsch, 1972). Soweit wir wissen, wurde jedoch noch von keinem anderen Polychaeten berichtet, der so viele verschiedene Schleimzelltypen in sich vereinigt. Die Frage, warum $A$. mucosa über so viele unterschiedliche Schleimzelltypen verfügt, ist zur Zeit kaum zu beantworten. Eine Erklärungsmöglichkeit wäre, daß die verschiedenen Schleimsorten nach Freisetzung miteinander reagieren und damit ein Schleimprodukt ergeben, das als Schutz gegenüber Feinden besonders effektiv ist. In diesem Zusammenhang wäre eine cytochemische Charakterisierung der Schleimzellen, wie sie beispielsweise an Sabella penicillum vorgenommen wurde (Kryvi, 1971), von besonderem Interesse.

Trotz der recht verschiedenen Feinstruktur der (mindestens) sechs morphologisch unterscheidbaren Schleimzelltypen von A. mucosa ist allen diesen Zellen gemeinsam, daß das Sekretprodukt nicht homogen, sondern in Paketen vorliegt. In einigen Fällen steht außer Zweifel, daß die Pakete von einer Membran umgeben sind, wie man es von der Genese her erwartet (vgl. Storch \& Welsch, 1972). In anderen Zellen ist kaum oder überhaupt keine Membran um die einzelnen Schleimpakete zu erkennen. Es bleibt offen, ob dieses Fehlen der Membran fixierungsbedingt ist oder ob es einen tatsächlich vitalen Zustand widerspiegelt.

Eine Sonderstellung unter den Schleimzellen nimmt der Typ ein, der durch eine periphere Mikrotubulilage charakterisiert ist. Für diese Mikrotubuli, die auch schon von Schleimzellen anderer Anneliden her bekannt sind (vgl. Storch \& Welsch, 1972), werden verschiedene Funktionen diskutiert. Unserer Meinung nach ist es am wahrscheinlichsten, daß diese Mikrotubuli eine Skelettfunktion haben. Unklar bleibt allerdings, weshalb nur ein Schleimzelltyp mit Mikrotubuli ausgekleidet ist, und nicht alle.

Die Extrusion des Schleims ist zumindest bei einigen Zellen mit einer starken Quellung des Sekretproduktes verknüpft, ein Mechanismus, der bis hinunter zu den Einzellern verfolgt werden kann. Bei bestimmten Ciliaten beispielsweise wird aus sogenannten Mucocysten fädiges Schleimmaterial unter dreidimensionaler Entfaltung und Streckung ausgeschieden (Hausmann, 1978).

Danksagungen. Für die Hilfe bei der Materialbeschaffung danke ich Herrn Dr. H. Michaelis, Forschungsstelle für Insel- und Küstenschutz, Norderney. Umsichtige und sorgfältige technische Assistenz leistete Frl. A. Rüskens. Herr Dr. W. Barthlott, Institut für Systematische Botanik der Universität Heidelberg, ermöglichte die rasterelektronenmikroskopischen Untersuchungen. Herrn Prof. Dr. V. Storch, Zoologisches Institut der Universität Heidelberg, danke ich für wertvolle Diskussionsbeiträge. 


\section{ZITIERTE LITERATUR}

Anton-Erxleben, F., 1977. Ein Beitrag zur Ultrastruktur der Elytrenoberflächen der Aphroditidae, Polynoidae und Sigalionidae (Polychaeta, Errantia, Nereimorpha). - Mitt. hamb. zool. Mus. Inst. $74,31-44$.

Barthlott, W. \& Ehler, N., 1977. Raster-Elektronenmikroskopie der Epidermis-Oberflächen von Spermatophyten. - Trop. subtrop. Pflanzenwelt 19, 367-467.

Dörjes, J., 1970. Das Watt als Lebensraum. In: Das Watt. Hrsg. von H.-E. Reineck. Kramer, Frankfurt, 71-105.

Eckelbarger, K. J. \& Chia, F.-S., 1978. Morphogenesis of larval cuticle in the polychaete Phragmatopoma lapidosa. - Cell Tiss. Res. 186, 187-201.

Ehlers, U. \& Ehlers, B., 1978. Paddle cilia and discocilia - genuine structures? - Cell Tiss. Res. 192, 485-501.

Farke, H. \& Hausmann, K., 1971. Untersuchung der Boden-Makrofauna als Nahrungspotential für Brut- und Gastvögel auf einer Wattfläche südöstlich Mellums. - Jber. ForschSt. Norderney 21, 101-118.

Franke, W. W., Krien, S. \& Brown, R. M. jr,, 1969. Simultaneous glutaraldehyde-osmium tetroxide fixation with postosmication. An improved fixation procedure for electron microscopy of plant and animal cells. - Histochemie 19, 162-164.

Friedrich, H., 1964. Die Haut der Anneliden. - Stud. gen. 17, 267-275.

Gardiner, S. L., 1978. Fine structure of the ciliated epidermis on the tentacles of Owenia fusiformis (Polychaeta, Oweniidae). - Zoomorphologie 91, 37-48.

Hausmann, K., 1978. Extrusive organelles in protists. - Int. Rev. Cytol. 52, 197-276.

Hausmann, K, 1980. Sessile Ciliaten auf Borstenwürmern. - Mikrokosmos 69, 156-159.

Holborow, P. L., 1971. The fine structure of the trochophore of Harmathoe imbricata. In: Fourth European marine biology symposium. Ed. by D. J. Crisp. Cambridge University Press, London, 237-246.

Holborow, P. L., Laverack, M. S. \& Barber, V. C., 1969. Cilia and other surface structures of the trochophore of Harmathoë imbricata (Polychaeta). - Z. Zellforsch. mikrosk. Anat. 98, 246-261.

Humphreys, S. \& Porter, K. R., 1976. Collagenous and other organizations in mature annelid cuticle and epidermis. - J. Morph. 149, 33-52.

Kryvi, H., 1971. Histology and histochemistry of the mucous glands of Sabella penicillum $L$. (Annelida, Polychaeta). - Norw. J. Zool. 19, 37-44.

Linke, O., 1939. Die Biota des Jadebusenwattes. - Helgoländer wiss. Meeresunters. 1, 201-348.

Mill, P. J., 1978. Sense organs and sensory pathways. In: Physiology of annelids. Ed. by P. J. Mill. Academic Press, London, 63-114.

Reynolds, E. S., 1963. The use of lead citrate at high $\mathrm{pH}$ as an electron opaque stain in electron microscopy. - J. Cell Biol. 17, 208-212.

Richards, K. S., 1978. Epidermis and cuticle. In: Physiology of annelids. Ed. by P. J. Mill. Academic Press, London, 33-61.

Schulte, E. \& Riehl, R., 1976. Elektronenmikroskopische Untersuchungen an den Tentakeln von Lanice conchilega (Polychaeta, Sedentaria). - Helgoländer wiss. Meeresunters. 28, 191-205.

Storch, V., 1971. Meeresborstenwürmer. Ziemsen, Wittenberg, $80 \mathrm{pp}$.

Storch, V. \& Alberti, G., 1978. Ultrastructural observations on the gills of polychaetes. - Helgoländer wiss. Meeresunters. 31, 169-179.

Storch, V. \& Welsch, U., 1970. Über die Feinstruktur der Polychaeten-Epidermis (Annelida). - Z. Morph. Tiere 66, 310-322.

Storch, V. \& Welsch, U., 1972. The ultrastructure of epidermal mucous cells in marine invertebrates (Nemertini, Polychaeta, Prosobranchia, Opistobranchia), - Mar. Biol. 13, 167-175.

Watson, M. L., 1958. Staining of tissue sections for electronmicroscopy with heavy metals. - J. biophys. biochem. Cytol. 4, 475-478.

Westheide, W: \& Rieger, R. M., 1978. Cuticle ultrastructure of hesionid polychaetes (Annelida). Zoomorphologie 91, 1-18. 